\title{
Risk of preterm delivery in gestations following the treatment of Cervical Intraepithelial Neoplasia (CIN) according to cone dimensions: systematic review
}

\author{
Beatriz Neves Teixeira¹, Caroline Teixeira Vieira de Carvalho¹, Rosane Ribeiro Figueiredo-Alves ${ }^{1 *}$ \\ 'Pontifícia Universidade Católica de Goiás (PUC Goiás), Escola de Ciências Médicas, Farmacêuticas e Biomédicas, Goiânia, GO, Brazil
}

\begin{abstract}
Background: There is evidence of increased risk of adverse events in subsequent pregnancies to CIN treatment. However, it is unclear what risk factors are associated with preterm delivery. Objective: To provide evidence for the association between excised uterine cervix dimensions and preterm delivery. Methodology: Systematic review about the association between the excised dimensions of the cervix and the occurrence of preterm birth in subsequent pregnancies after CIN treatment. The survey was conducted in the PUBMED database from 2004 to 2015, in the English language. It was excluded articles that, although they assessed complications in subsequent pregnancies after CIN treatment, did not evaluate association between cone dimensions and preterm birth occurrence. Results: It was included eight retrospective cohorts, one prospective cohort and one case-control study. The number of participants in ten studies was 8.185. The association between preterm birth and cone depth was evidenced in eight studies and not shown in two. Four studies evaluated the relationship between excised volume and preterm birth, with discordant results. The number of conizations was evaluated in six studies, with results also discordant. Conclusion: It is unclear whether the excised tissue dimensions would be isolated risk factors for preterm delivery.
\end{abstract}

Keywords: Cervical Intraepithelial Neoplasia; preterm delivery; conisation; dimensions.

\section{Introduction}

Cervical cancer is the third most frequent malignant disease in woman and one of the main death causes by neoplasia at developing countries. ${ }^{1}$ In Brazil accordingly with National Cancer Institute (INCA) estimates, there was 16.340 new cases in 2016; and in the Midwest region, the estimate incidence for 2016 reached 1.560 cases. $^{2}$

Although it represents a public health problem, the cervical cancer is preventable, once it slowly evolves from CIN, which can be screened by cytological exam. Thus the implementation of planned programs of cytological screening provided a significant reduction in incidence and mortality in developed countries.,4 The population coverage and the interval between the screening and the proper conduction of women with cytological abnormalities, are considered the critical ingredients of the cervical cancer prevention programs. ${ }^{3-6}$

The abnormalities detected by cytological screening represent a common problem. Estimations point to approximately 7 to $10 \%$ of women submitted to screening have some degree of abnormality. ${ }^{5}$ The excision is the proposed treatment for women with cytological abnormalities and precursory lesions, defined as CIN 2 and CIN 3, due to the atypias that compromise respectively two thirds and all epithelial thickness. ${ }^{5,6}$ The treatment may be conducted by cold knife conization, electrosurgery or by laser. The resection through electrosurgery, introduced by Prendville in 1989, has gained quick acceptance by providing a proper sample for histopathological examination, convenience for outpatient

\footnotetext{
Financial support: None.

Conflicts of interest: The authors declare no conflicts of interest.

Submitted: May 19, 2017.

Accepted: October 18, 2017.

The study was carried out at Pontifícia Universidade Católica de Goiás (PUC Goiás), Escola de Ciências Médicas, Farmacêuticas e Biomédicas, Goiânia, GO, Brazil.

Copyright Teixeira et al. This is an Open Access article distributed under the terms of the Creative Commons Attribution License, which permits unrestricted use distribution, and reproduction in any medium, provided the original work is properly cited.
} 
implementation under local anesthesia, combined with high cure rates and low morbidity. ${ }^{7,8}$ Nevertheless there are strong evidence of adverse effects resulting from such resections on progress of further pregnancies such as preterm birth, preterm premature rupture of membranes and low birth weight; regardless of the technique applied. ${ }^{9}$ However few studies evaluated the relation between the size of conization and the occurrence of preterm birth.

\section{Materials and methods}

It was realized a systematic review by analysis of articles that approached the link between the excised measures of uterine cervix and the occurrence of preterm birth in subsequent pregnancies in CIN 2 and CIN 3 cases. The bibliographic research was conducted in PUBMED database and has included studies published in English between 2014 and 2015. The key words used were "cervical intraepithelial neoplasia", "pregnancy outcomes", "loop electrosurgical excision procedure and dimensions". It was excluded articles that did not assessed the association between the dimensions of the excised samples and the preterm birth occurrence

\section{Results}

Ten articles were selected, of which eight were retrospective cohorts, one prospective cohort and one case-control study. Six studies included participants submitted only to electrosurgical resection of the injury ${ }^{10-15}$ and four studies included patients undergoing to different combinations of electrosurgical resection, classic conization and ablation or excision through Laser. ${ }^{16-19}$ The global number of participants were 8.059. Nine of the studies were conducted at Europe and one at New Zealand.

All included studies highlighted the link between conization and occurrence of adverse events in subsequent pregnancies. ${ }^{10-19}$ However with the analysis restricted to the dimensions of the cone, the association between preterm birth and cone's depth, measure of the external cervix opening in the internal or stromal margin of the excision was emphasized in eight studies, ${ }^{11,12,14-19}$ and was not found in two. ${ }^{10,13}$

Four studies have assessed the volume of the excised sample. ${ }^{10,12,14,19}$ One of them examined the cervix dimensions by magnetic resonance imaging and ultrasound before and after the conization. This study has shown an association between the volume of the excised tissue and the incidence of preterm birth. ${ }^{14}$ Another three studies evaluated the volume of the tissue excised and fixed in formalin. One of them found association between preterm birth and volume ${ }^{12}$, the other two did not. ${ }^{10,19}$

The assessment of the number of conizations was evaluated in six studies. 10,11,13,17-19 Two of them shown relation between preterm birth and number of conizations and four of them did not find this association.

\section{Discussion}

Strong evidences have shown that women submitted to treatment of cancer precursor injuries at cervix, by any available method, present an increased risk for adverse events in subsequent pregnancies. ${ }^{9}$ Due to the unknown cause of this association, recently studies listed in Table 1 evaluated the impact of the dimensions of excised tissue on the risk increase of preterm birth.

Several studies have evidenced an increased risk with higher cone depth.11,12,14-19 The risk of preterm birth is minimum for excision smaller than 10 to $15 \mathrm{~mm}$ dept. 12,15,18,19 According with the results of a case control study with 1.114 conizations, this risk was similar to those found in women submitted only to cervix biopsy without need a subsequent conization. ${ }^{19}$ However in the same study, excisions above 10 to $15 \mathrm{~mm}$ and excised volume over than $2.66 \mathrm{~cm}^{3}$ were related with increased risk of preterm and extreme preterm birth. ${ }^{19}$ According with these studies efforts should be done in order to excise the entire injury, however with the preservation of as many healthy cervix tissue as possible.

There are controversies regarding the association between preterm birth with depth and volume of the excised tissue. In two retrospective cohorts involving 571 and 556 women submitted to conizations, there was not an evidence of this relation. ${ }^{10,13}$ These results suggest that the reduction of the cervix length would not be the only responsible factor for preterm birth. Under these results, the conization should be performed with adequate tissue in order to ensure a complete resection of the disease.

In another study, the dimension of the cone before and after conization were evaluated by ultrasound and magnetic resonance imaging (MRI) and correlated with pregnancy length in 16 women. There was a substantial variation in volume and excision depth, before and after treatment. However the bigger proportion of excised tissue presented correlation with pregnancy length. These data suggest that the assessment of the proportion excised, and not only the volume or depth, might help to stratify women at risk of preterm birth. ${ }^{14}$ 
Table 1. List of studies evaluating the association between preterm birth and cone size in women undergoing treatment of cervical intraepithelial neoplasia grade 2/3 (CIN 2/3)

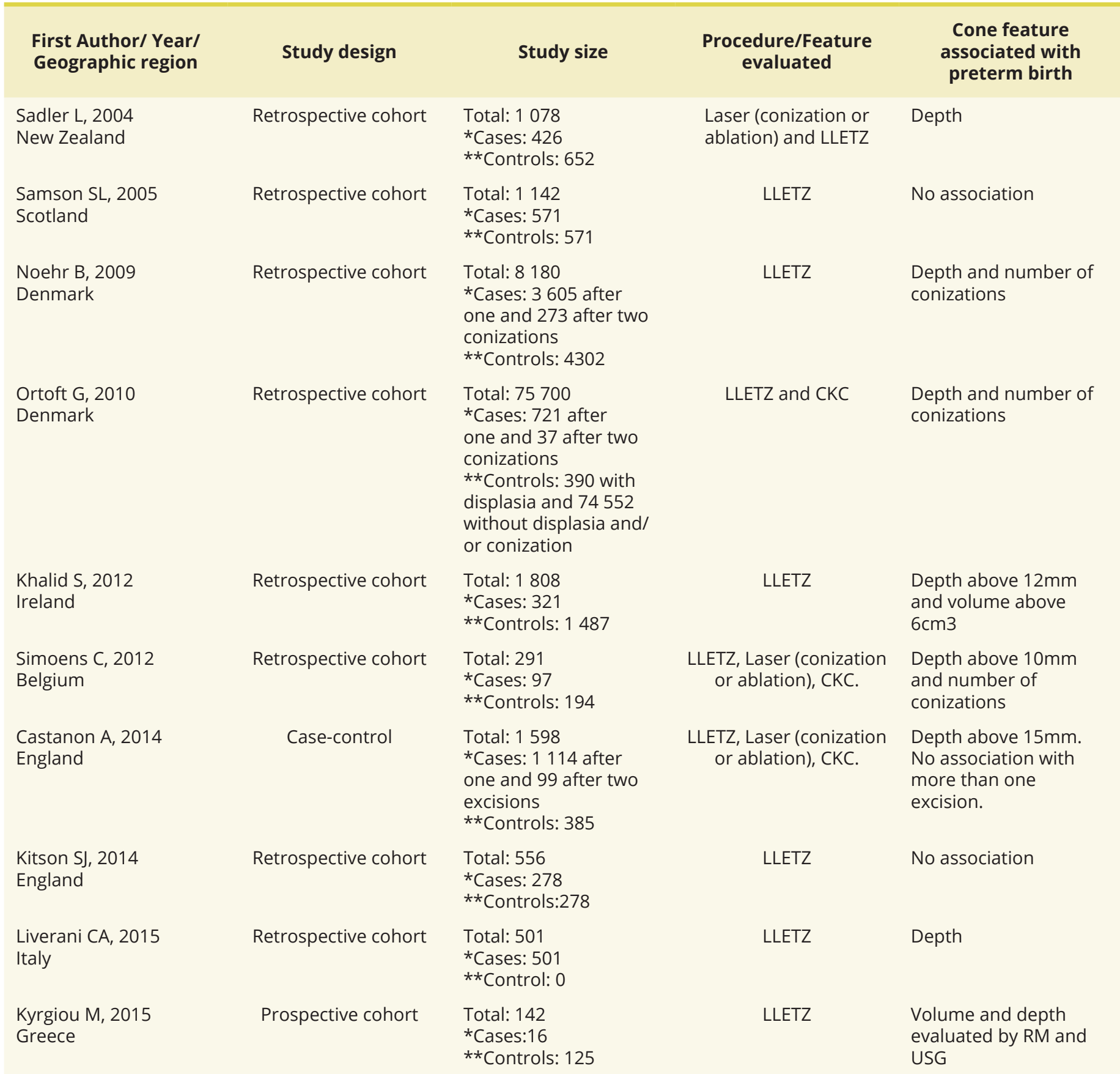

*Cases: number of participants with single pregnancy after treatment for HG-CIN; ${ }^{* *}$ Controls: number of participants with a single pregnancy who did not undergo treatment for CIN 2/3; LLETZ: large loop excision of transformation zone; CKC: cold knife conisation.

Other studies included in this review evaluated the association between premature birth and volume of excised tissue. These studies highlighted that excisions above $2,66 \mathrm{~cm}^{3}$ were related with both premature and extreme premature births. ${ }^{12,19}$ This risk increase could be consequence of total excised depth. ${ }^{19}$ However other studies did not find relation between preterm birth and volume of the cone. $13,15,17,18$ Likewise there is evidences that the transverse diameter and circumference does not have adverse effect on pregnancy. ${ }^{15,17}$

Other studies also evaluated the effect of the number of conizations upon subsequent pregnancies. Some of these studies shown that more than one conization is strongly related with premature birth, 11,17,18 but others did not show 
this relationship. ${ }^{10,13,19}$ The increased risk in women undergoing multiple excision could be an implication of the total excised depth.

In accordance with our results, the increase of preterm birth risk related with the cone dimensions its not fully clarified, and some considerations about the design of this studies (level of evidence B) must placed. The first refers to the definition of control group, which presented high variability. Only three of the ten studies compared women submitted to conization with $\mathrm{CIN}$ and women with CIN that undergone only to biopsy, and did not required conization (Ortoft et al. 2010; Castanon et al. 2014; Kitson et al. 2014). ${ }^{13,17,19}$ Furthermore, considering the shared risk factors of $\mathrm{CIN}$ and premature parturition such as age, socioeconomic status, smoking and highest prevalence of genital infections, these data should be taken into account in the experimental design, however they were present only in two studies. Therefore the occurrence of premature birth could be consequence of CIN associated factors, and not of its treatment.

Beyond the election of control group and confounding factors, the evaluation of the removed tissue must be also standardized. The ideal technique for volume determination would be one that considers fluid displascement ${ }^{20}$ and not by review of the histopathological exam, as did in those studies. ${ }^{14}$

Another important observation is that the degree of functional injury on cervix will probably rely beyond the cone dimension, but also depend of the thermic damage caused by the excision or the hemostasis of electrosurgery; variables that are not available through excised tissue measures. If this injury occurs, could be resulting of the resection of a large amount of stroma, which even after regenerated would not have the same functional properties of a tissue without surgical scars.

There are strong evidences about the association between the treatments for cervical cancer precursory lesions and negative effects in following pregnancies, which may include premature birth, premature rupture, preterm premature rupture of membranes and low birth weight. ${ }^{9}$ But according to this review, it is still not clear it the dimensions of the excised tissue would be single risk factor for preterm birth. Therefore women considering a future pregnancy should be clarified about this. As a result, efforts should be made to excise the entire injury, through colposcopy view in order to modular the cone depth, with maximum preservation of healthy cervix tissue as possible. Also may have a role for the increase of the prenatal surveillance, with regular checks of length and dilatation of cervix by digital exams and/or transvaginal ultrasound in those women.

\section{References}

1. ZURHAUSEN H. Papillomavirus in the causation of human cancers: a brief historical account. Virology. 2009;384:260-5.

2. Instituto Nacional do Câncer. Estimativas de incidência de câncer no Brasil [Internet] 2016 [cited 2017 May 17]. Available from: http://www.inca.gov.br/estimativa/2012/index.asp?ID=5

3. MEIJER CJL, WALBOOMERS JMM. Cervical cytologic after 2000: Where to go? J Clin Pathol. 2000;53:41-3.

4. PATNICK J. Cervical cancer screening in England. Eur J Cancer. 2000;35:2335-9.

5. MASSAD LS, EINSTEIN MH, HUH WK, KATKI HA, KINNEY WK, SCHIFFMAN M, et al. 2012 Updated Consensus Guidelines for the Management of Abnormal Cervical Cancer Screening Tests and Cancer Precursors. Obstet Gynecol. 2013;121(4):829-46.

6. InstitutoNacional de Câncer. Diretrizes Brasileiras para o Rastreamento do Câncer do Colo do Útero [Internet]. Rio de Janeiro: Ministério da Saúde; 2016 [cited 2017 May 17]. Available from: http://citologiaclinica.org.br/site/pdf/documentos/diretrizes-parao-rastreamento-do-cancer-do-colo-do-utero_2016.pdf

7. PRENDIVILLE W, CULLIMORE NS. Large loop excision of the transformation zone (LLETZ): a new method of management for women with cervical intraepithelial neoplasia. Br J Obstet Gynaecol. 1989;96:1054-60.

8. LINDEQUE BG. Management of cervical premalignant lesions. Best Pract Res Clin Obstet Gynaecol. 2005;19:545-61.

9. KYRGIOU M, KOLIOPOULOS G, MARTIN-HIRSCH P, ARBYN M, PRENDIVILLE W, PARASKEVAIDIS E. Obstetric outcomes after conservative treatment for intraepithelial or early invasive cervical lesions: systematic review and meta-analysis. Lancet. 2006;367(9509):489-98.

10. SAMSON SL, BENTLEY JR, FAHEY TJ, MCKAY DJ, GILL GH. The effect of loop electrosurgical excision procedure on future pregnancy outcome. Obstet Gynecol. 2005;105:325-32.

11. NOEHR B, JENSEN A, FREDERIKSEN K, TABOR A, KJAER SK. Depth of cervical cone removed by loop electrosurgical excision procedure and subsequent risk of spontaneous preterm delivery. Obstet Gynecol. 2009;114:1232-8.

12. KHALID S, DIMITRIOU E, CONROY R, PARASKEVAIDIS E, KYRGIOU M, HARRITY C, et al. The thickness and volume of LLETZ specimens can predict the relative risk of pregnancy-related morbidity. BJOG. 2012;119:685-91.

13. KITSON SJ, GREIG E, MICHAEL E, SMITH M. Predictive value of volume of cervical tissue removed during LLETZ on subsequent preterm delivery: a cohort study. Eur J Obstet Gynecol Reprod Biol. 2014;180:51-5.

14. KYRGIOU M, VALASOULIS G, STASINOU S-M, FOUNTA C, ATHANASIOU A, BENNETT P, et al. Proportion of cervical excision for cervical intraepithelial neoplasia as a predictor of pregnancy outcomes. Int J Gynaecol Obstet. 2015;128(2):141-7. 
15. LIVERANI CA, DI GIUSEPPE J, CLEMENTE N, CARPINI GD, MONTIA E, FANETTIA F, et al. Length but not transverse diameter of the excision specimen for high-grade cervical intraepithelial neoplasia (CIN 2-3) is a predictor of pregnancy outcome. Eur J Cancer Prev. 2015;25(5):416-22.

16. SADLER L, SAFTLAS A, WANG W, EXETER M, JOHN WHITTAKER J, MCCOWAN L. Treatment for Cervical Intraepithelial Neoplasia and Risk of Preterm Delivery. JAMA. 2004;291(17):2100-6.

17. ORTOFT G, HENRIKSEN T, HANSEN E, PETERSEN L. After conisation of the cervix, the perinatal mortality as a result of preterm delivery increases in subsequent pregnancy. BJOG. 2010;117:258-67.

18. SIMOENS C, GOFFIN F, SIMON P, BARLOW P, ANTOINE J, FOIDART J, et al. Adverse obstetrical outcomes after treatment of precancerous cervical lesions: a Belgian multicentre study. BJOG. 2012;119:1247-55.

19. CASTANON A, LANDY R, BROCKLEHURST P, EVANS H, PEEBLES D, SINGH N, et al. PaCT Study Group. Risk of preterm delivery with increasing depth of excision for cervical intraepithelial neoplasia in England: nested case-control study. BMJ. 2014;349:g6223.

20. LIMA NL. Estudo sobre o cálculo de áreas e volumes utilizando o Método de Exaustão e o Princípio de Cavalieri [dissertação]. Joao Pessoa: Universidade Federal da Paraíba; 2013.

\section{*Correspondence}

Rosane Ribeiro Figueiredo Alves

Pontifícia Universidade Católica de Goiás (PUC Goiás), Escola de Ciências Médicas, Farmacêuticas e Biomédicas

CEP 746050-10, Goiânia, GO, Brazil

Tel.: +55 (62) 3946-1486

E-mail: rosanefalves@gmail.com

\section{Author information}

BNT and CTVC - Students of the Departamento de Medicina da Escola de Ciências Médicas, Farmacêuticas e Biomédicas da Pontifícia, Universidade Católica de Goiás. RRFA - Adjunct professor, MD, PhD of the Departamento de Medicina da Escola de Ciências Médicas, Farmacêuticas e Biomédicas da Pontifícia Universidade Católica de Goiás.

\section{Authors contribution}

RRFA - was responsible for the study design, coordination, search in databases, and wrote the manuscript. BNT and CTVC - helped in the database search and in the making of the tables. 